\title{
Influence of Coronavirus 2 Pandemic on Acute Surgical Abdomen in Pediatrics: Retrospective Cohort Study
}

\section{Claudio Racana ${ }^{1,3}$, Ignacio Alonso ${ }^{1,4}$, Marcelo Barrenechea ${ }^{1,5}$, Romina

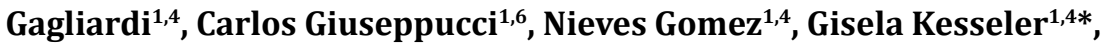 Ignacio Montes $^{1,4}$, Ana Laura Naso ${ }^{1,4}$, Carolina Perez Espinoza ${ }^{1,7}$, Matías Sprovieri ${ }^{1,4}$ and Luis Gamba ${ }^{1,2}$}

${ }^{1}$ Pediatric Hospital "Prof. Dr. Juan P. Garrahan”, Combate de los Pozos 1881, Ciudad

Autónoma de Buenos Aires, Argentina

${ }^{2}$ UDECIP Coordinator (Peri-surgical Comprehensive Clinical Evaluation Unit),

Pediatric Hospital "Prof. Dr. Juan P. Garrahan", Argentina

${ }^{3}$ Head of Clinic of UDECIP, Pediatric Hospital "Prof. Dr. Juan P. Garrahan", Argentina

${ }^{4}$ Assistant Physician of UDECIP, Pediatric Hospital "Prof. Dr. Juan P. Garrahan",

Argentina

${ }^{5}$ Head of General Surgery Service, Pediatric Hospital "Prof. Dr. Juan P. Garrahan",

Argentina

${ }^{6}$ Assistant Physician of General Surgery Service, Pediatric Hospital "Prof. Dr. Juan P.

Garrahan", Argentina

${ }^{7}$ Head of Residents of General Surgery Service, Pediatric Hospital "Prof. Dr. Juan P.

Garrahan", Argentina

*Corresponding Author: Gisela Kesseler, Pediatric Hospital “Prof. Dr. Juan P. Garrahan”, Combate de los Pozos 1881, Ciudad Autónoma de Buenos Aires, Argentina.

\section{Abstract}

Purpose: Retrospective evaluation of Coronavirus 2 (SARS-Cov-2) associated with surgical acute abdomen in our hospital.

Methods: Observational and retrospective study, that includes patients age 0-18 years old, whose diagnosis was surgical acute abdomen. The evaluated periods were April to June 2019 and April to June 2020. The variables have been analyzed: demographics, clinical history, current preoperative disease, surgical procedure and evolution.

Results: Study included 205 patients, 127 from 2019 (0.6\% of procedures) and 78 from 2020 (1.7\% of procedures). In 2020 patients took longer to consult and longer delay in entering the operating room. There were no significative differences about severe forms of presentation or complications. Either were no differences into hospital stay.

Conclusion: SARS-Cov-2 pandemic had no influence on the evaluated patients. Also protocolizing inpatient care had no negative impact on patients. It is important to highlight that SARS-Cov-2 gets confused with surgical acute abdomen in pediatric patients.

Keywords: Acute Abdomen; Betacoronavirus; Appendectomy; Pediatrics; Postoperative Complication 


\section{Introduction}

Surgical acute abdomen is the most frequent surgical emergency in pediatrics. In emergency services $1-8 \%$ of the patients are diagnosed with acute appendicitis.

SARS-Cov-2 can be associated with gastrointestinal symptoms, so it can cause confusion to establish the diagnosis.

Early diagnosis and treatment are important to decrease advanced forms and complications.

Appendectomy is the best treatment when surgical acute abdomen is diagnosed.

There are no enough publications to analyze pandemic impact on surgical acute abdomen.

It was imperative to protolyze patients who had to be operated during SARS-Cov-2 pandemic. Protocol includes presurgical swab for every patient (since 2020, May $4^{\text {th }}$ ), different transfer circuit and do not use laparoscopic technique. All these changes were necessary to protect health team, without having consequences for patients.

\section{Purpose of the Study}

The main purpose of the study is to evaluate SARS-Cov-2 pandemic impact over surgical acute abdomen's diagnosis, evolution and treatment. Also, it is significant to analyze the importance of presurgical swab in the least exposure of the health team.

\section{Population and Methods}

This is an observational, descriptive and retrospective study. It includes patients age 0 - 18 years old, who were admitted in the hospital with surgical acute abdomen, between April to June 2019 and April to June 2020. Patients with a diagnosis of acute abdomen who did not have surgical redress were excluded.

So, the patients were classified in two groups: 2019 (before SARS-Cov-2 pandemic) and 2020 (during SARS-Cov-2 pandemic). It is important to clarify that the health emergency was declared in Argentina on 2020, March $12^{\text {th }}$ and preventive and compulsory social isolation was declared on 2020, March $20^{\text {th }}$.
The data was obtained in computerized medical records of our hospital. The information was analyzed with Google Sheets.

The evaluated variables were: demographics, clinical history, current preoperative disease, surgical procedure and evolution.

Appendicitis were classified into 2 groups:

- $\quad$ Not complicated appendicitis, that include normal, phlegmonous and congestive appendix;

- $\quad$ Peritonitis, that include localized and generalized peritonitis.

Complications were classified by STROC (Stratification of Complications), using 1 to 5 scale.

STROC I (minor, self-limited complications) and STROC II (need drug treatment and double the hospital stay) are classified like low complexity.

STROC III (require surgical, endoscopic and percutaneous treatment), STROC IV (require intensive care unit, risk of life) and STROC $\mathrm{V}$ (surgery -related death) are classified like severe complexity.

As numerical variables study used mean or median summary measures, and dispersion measures, like standard deviation or range. Proportions or percentages were used for the categorical variables. These variables were compared with the Fisher test. The value of $\mathrm{p}<0.05$ was considered statistically significant and all the intervals were calculated with a confidence of $95 \%$.

\section{Results}

The study included 205 patients with acute surgical abdomen diagnosis, 127 patients from 2019. This represents 4\% of outpatient consultations out of a total of 21395 inquires, and $0.6 \%$ of the surgeries, of 3140 surgeries perform.

From 2020, were included 78 patients. This represents $6.9 \%$ of outpatient consultations out of a total of 4451 inquires, and $1.7 \%$ of the surgeries, of 1137 surgeries perform.

The average age for the 2019 group was 9.23 years old (SD 3.7) and for the 2020 group was 10.32 years old (SD 3.3). Table 1 shows the main categorical descriptive variables analyzed. 


\begin{tabular}{|l|c|c|c|}
\hline & $\begin{array}{c}\mathbf{2 0 1 9} \\
(\mathbf{n = 1 2 7}) \\
\mathbf{n}(\mathbf{\%})\end{array}$ & $\begin{array}{c}\mathbf{2 0 2 0} \\
(\mathbf{n = 7 8}) \\
\mathbf{n}(\mathbf{\%})\end{array}$ & $\begin{array}{c}\mathbf{p}- \\
\text { value }\end{array}$ \\
\hline Gender & & & \\
\hline Femenine & $54(42.5)$ & $25(32.1)$ & 0.1384 \\
\hline Male & $73(57.5)$ & $53(67.9)$ & 0.1384 \\
\hline
\end{tabular}

\begin{tabular}{|l|l|l|l|}
\hline Prior consultation in a less com- $46(36.2)$ & $17(21.8)$ & 0.0304 \\
\hline
\end{tabular} plex center

Weight percentile (p)

Less than or equal to the $3^{\text {rd }}$ per-

centile

\begin{tabular}{|l|l|l|l|l|}
\hline Greater than the $3^{\text {rd }}$ percentile & $90(70.9)$ & $46(59.0)$ & 0.0807
\end{tabular}

and less than or equal to the $90^{\text {th }}$

percentile

\begin{tabular}{|l|l|l|l|}
\hline Greater than the $90^{\text {th }}$ percentile & $34(26.8)$ & $26(33.3)$ & 0.3219 \\
\hline
\end{tabular}

\begin{tabular}{|l|l|l|l|}
\hline Presence of underlying disease & 22 (17.3) & 27 (34.6) & 0.0049 \\
\hline
\end{tabular}

Signs and Symptoms

Abdominal Pain

Nausea and vomiting

Fever

Diarrhea

Dehydration

Sepsis

Urinary symptoms

Sensorium altered

Presurgical leukocytes (/ $\left.\mathbf{m m}^{3}\right)$

$5000-15000$

$<5000$ - > 15000

Presurgical PCR SARS-Cov-2

Detectable

Not detectable

Unrealized

Presurgical Image

Abdominal x-ray

Abdominal ultrasound

Abdominal tomography

Boarding technique

Convencional

Laparoscopic

Surgical diagnosis

Not complicated appendicitis

Gangrenous appendicitis

Peritonitis $^{2}$

Appendicular plastron

Complications

No

Minors $^{3}$

Severes $^{4}$

\begin{tabular}{|c|c|c|}
$77(60.6)$ & $42(53.8)$ & 0.3394 \\
\hline
\end{tabular}

30 (23.6) 17 (21.8) 0.7665

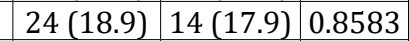

\begin{tabular}{l|l|l|}
$9(7.1)$ & $6(7.7)$ & 0.8732 \\
\hline
\end{tabular}

\begin{tabular}{|l|l|l|}
\hline $1(0.8)$ & $2(2.6)$ & 0.3021 \\
\hline
\end{tabular}

\begin{tabular}{|l|l|l|}
0 & $1(1.3)$ & 0.1988 \\
\hline
\end{tabular}

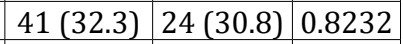

\begin{tabular}{ll|l|l|}
$86(67.7)$ & $54(69.2)$ & 0.8232 \\
\hline
\end{tabular}

\begin{tabular}{|l|l|l|}
\hline & & \\
\hline 0 & $3(3.8)$ & 0.0273 \\
\hline
\end{tabular}

\begin{tabular}{c|c|c}
0 & $3(3.8)$ & 0.027 \\
0 & $31(39.7)$ & $<$
\end{tabular}

\begin{tabular}{l|c|c|} 
& & 0.0001 \\
\hline $127(100)$ & $44(56.4)$ & $<$
\end{tabular}

0.0001

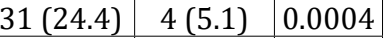

$82(68.5) \quad 55(78.2) \quad 0.1333$

\begin{tabular}{l|l|l|}
\hline $1(0.8)$ & $1(1.3)$ & 0.7262 \\
\hline
\end{tabular}

$83(65.4) \quad 61(78.2) \quad 0.0521$

\begin{tabular}{|l|l|l|}
$44(34.6)$ & $17(21.8)$ & 0.0521 \\
\hline
\end{tabular}

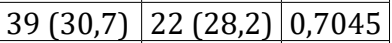

$33(26,0) 25(32,1) \quad 0,3478$

$51(40,2) \quad 30(38,5) \quad 0,8095$

\begin{tabular}{l|l|l|}
$4(3,1)$ & $1(1,3)$ & 0,4162 \\
\hline
\end{tabular}

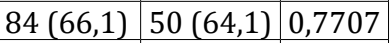

$41(32,3) \quad 27(34,6) \quad 0,7348$

\begin{tabular}{l|l|l|}
$2(1,6)$ & $1(1,3)$ & 0,8365 \\
\hline
\end{tabular}

\begin{tabular}{|l|c|c|c|}
\hline Unfavorable evolution & & & \\
\hline Intensive care unit & $2(1,6)$ & 0 & 0,2627 \\
\hline Deaths & 0 & 0 & - \\
\hline
\end{tabular}

Table 1: Descriptive data. Categorical variables.

${ }^{1}$ Not complicated appendicitis, that include normal, phlegmonous and congestive appendix.

${ }^{2}$ Localized and generalized peritonitis.

${ }^{3}$ Minor complications: STROC I (minor, self-limited complications) and STROC II (need drug treatment and double the hospital stay).

${ }^{4}$ Severe complications: STROC III (require surgical, endoscopic and percutaneous treatment), STROC IV (require intensive care unit, risk of life) and STROC V (surgery-related death).

Time of delay in consulting and relationship with serious form

Although, in the evaluation it was seen that patients took 3 days to consult, in 2019 medical consultation tended to be earlier, with a median range of 1 day (range 1 - 15), compared to 2020. This year the median range was 1.5 days (range 1 - 7) (Figure 1).

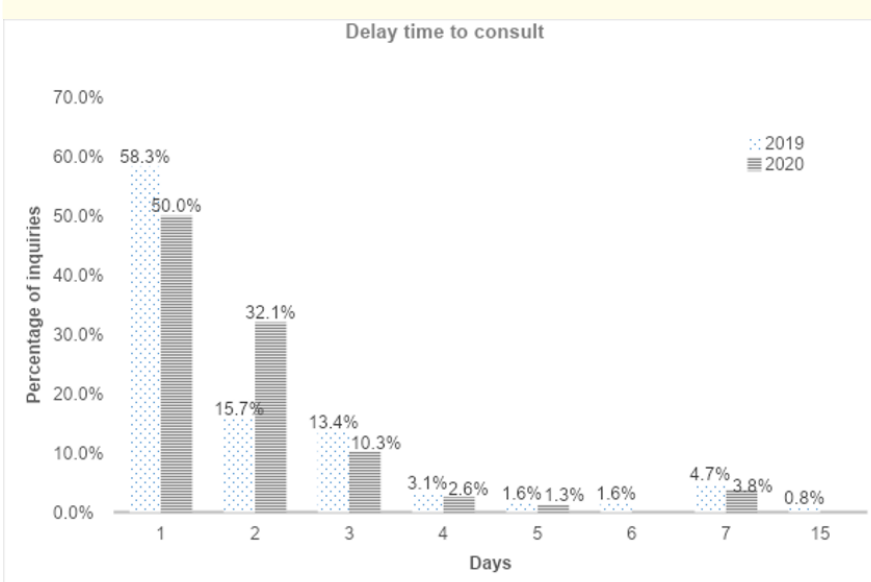

Figure 1: The percentage of consultations is described for each day of delay in consulting in the 2 study groups.

Patients that had diagnosis of peritonitis consulted with a median range of 2 days (range 1 - 7), and those who required postoperative drainage consulted with a median range of 3 days (range 
2 - 7) in 2019, and median range of 3 days (range 1 - 7) in 2020.

There was no difference between both groups (Table 2).

\begin{tabular}{|l|c|c|}
\hline & $\begin{array}{c}\mathbf{2 0 1 9} \\
\text { Median in } \\
\text { days [range] }\end{array}$ & $\begin{array}{c}\mathbf{2 0 2 0} \\
\text { Median in } \\
\text { days [range] }\end{array}$ \\
\hline Not complicated appendicitis $^{1}$ & $1[1-15]$ & $1[1-3]$ \\
\hline Gangrenous appendicitis $^{2}$ & $1[1-7]$ & $1[1-5]$ \\
\hline Peritonitis $^{2}$ & $2[1-7]$ & $2[1-7]$ \\
\hline With complications & $1[1-7]$ & $2[1-7]$ \\
\hline Without complications & $1[1-15]$ & $1[1-5]$ \\
\hline With posoperative drainage & $3[2-7]$ & $3[1-7]$ \\
\hline Without posoperative drainage & $1[1-15]$ & $1[1-7]$ \\
\hline
\end{tabular}

Table 2: Relationship of time delay in consulting with the surgical diagnosis and complications.

${ }^{1}$ Include normal, phlegmonous and congestive appendix.

${ }^{2}$ Include localized and generalized peritonitis.

Time of delay in entering to surgery and its relationship with the most serious form

Regarding the time of delay in entering to surgery, a median of 9.8 hours was seen in 2019 group (range 1.55 - 52.2), and a median of 14.7 hours in 2020 group (range 0.7 - 71.6).

When it was analyzed month by month, an increase in the delay was noticeable, accentuating that in months of May and June of 2020 (Table 3).

\begin{tabular}{|l|c|c|c|c|c|c|}
\hline & $\begin{array}{c}\text { 2019- } \\
\text { April }\end{array}$ & $\begin{array}{c}\text { 2019- } \\
\text { May }\end{array}$ & $\begin{array}{c}\text { 2019- } \\
\text { June }\end{array}$ & $\begin{array}{c}\text { 2020- } \\
\text { April }\end{array}$ & $\begin{array}{c}\text { 2020- } \\
\text { May }\end{array}$ & $\begin{array}{c}\text { 2020- } \\
\text { June }\end{array}$ \\
\hline $\begin{array}{l}\text { Median } \\
\text { in hours }\end{array}$ & 10.7 & 9.4 & 9.8 & 8.7 & 14.9 & 26.3 \\
\hline Range & $2.0-51.3$ & $1.5-52.2$ & $2.2-48.0$ & $0.7-71.6$ & $3.1-46.5$ & $3.8-32.9$ \\
\hline
\end{tabular}

Table 3: Time delay to enter operating room in hours.

When analyzing if this had an implication in the appearance of more serious forms, it was seen that the percentage of complications was similar in all the evaluated periods. A significant difference stands out in April 2020, when it was observed that those who presented complications they took 25.6 hours on average to enter (SD 28.7) versus those who did not present complications that took 11 hours an average to enter (SD 10.7), as shown in figure 2. Re- garding the appearance of peritonitis, in 2019 it was seen that the median hours of delay in entering the operating room were greater than the not complicated appendicitis (Table 4).

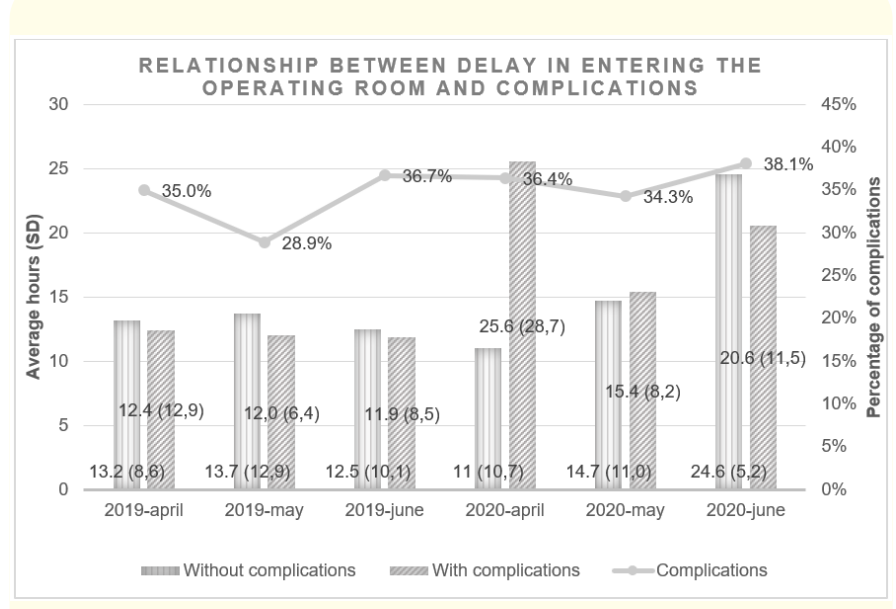

Figure 2: The bars on the left of each month express the average (SD) hours of delay in entering the operating room for NOT complicated and those on the right of those who did. The line shows the variation in the percentage of complications.

\begin{tabular}{|l|c|c|}
\hline & $\begin{array}{c}\mathbf{2 0 1 9} \\
\text { Median in } \\
\text { hours [range] }\end{array}$ & $\begin{array}{c}\mathbf{2 0 2 0} \\
\text { Median in } \\
\text { hours [range] }\end{array}$ \\
\hline $\begin{array}{l}\text { Not complicated appendici- } \\
\text { tis }^{1}\end{array}$ & $10.3[2.0-52.2]$ & $17.4[0.7-67.7]$ \\
\hline Gangrenous appendicitis $^{2}$ & $7.7[2.5-26.3]$ & $11.9[3.1-32.9]$ \\
\hline Peritonitis $^{2}$ & $12,1[1.5-51.3]$ & $13.7[1.5-71.6]$ \\
\hline
\end{tabular}

Table 4: Relationship between the delay in entering the operating room and the surgical diagnosis.

${ }^{1}$ Include normal, phlegmonous and congestive appendix.

${ }^{2}$ Include localyzed and generalyzed peritonitis.

Relationship between the surgical boarding technique and postoperative complication

En el grupo del 2020 se observó un 40\% de complicaciones en los que se abordaron por vía laparoscópica versus los que se abordaron por vía convencional que se complicaron en un $34.4 \%$ 
(p 0.6718). Para el año 2019 se vio un 31.8\% de complicaciones en los abordados por vía laparoscópica y $34.9 \%$ en los abordados por vía convencional (p 0.7264).

In 2020 group of study, $40 \%$ of complications were observed in those that were boarded with a laparoscopic technique versus $34.4 \%$ (p 0.6718 ) for those that were boarded conventionally. In $2019,31.8 \%$ of complications were seen in laparoscopic technique and $34.9 \%$ in conventional (p 0.7264).

\section{Hospital stay}

Regarding the hospital stay, a median of 4 days was observed in 2019 (range 1-101) and for 2020 a median of 4.5 days (range 1 - 29).

\section{Discussion}

In our work we have observed, in the pandemic stage (2020), a higher percentage of acute surgical abdomen compared to the same period in 2019. In turn, the percentage of patients who went directly to a high complexity hospital was higher, without having consulted before to another center. This point probably in relation to fewer consultation places available that can solve pediatric surgical pathology. In this regard, non-surgical treatment could be considered in uncomplicated appendicitis, which would help to alleviate these shortcomings, as was proposed in some centers, prior to the onset of the pandemic. However, in the study by Huang L., et al. the results of adopting this strategy shows an increase in hospital stay and appendectomies due to poor clinical evolution [1].

Analyzing the antecedents of the population and the delay to consult, we saw that in the pandemic stage the percentage of patients with underlying disease and patients at the extremes of weight percentiles (below p3 and above p90) was significantly higher. Patients with peritonitis and required postoperative drainage those with the greater delays to consult.

Already in the in-hospital stage, the delay in entering the operating room was notorious, particularly in May and June 2020, after having protocolized the swabbing for pre-surgical SARS-Cov-2. The delay has not being related to severe forms or the appearance of complications, with the exception of April 2020, when it was observed that patients who had complications had taken longer to enter the operating room. In April 2020, the pre-surgical protocol for the pandemic was not yet in place in our center. Regarding the re- lationship between the time delay in entering the operating room and the appearance of peritonitis, the results were inconclusive.

The delay in entering the operating room in the pandemic stage may have been related to the diagnostic confusion due to gastrointestinal symptoms that SARS-cov-2 has shown to cause, according to various investigations [2-5]. However, all our analyzed patients had symptoms justified by the surgical pathology, in addition to the fact that the longest delay was after establishing the pre-surgical protocol, then this delay in entering the operating room would seem to be more related to waiting for the result of the pre surgical swabbing than with late diagnosis.

In the study by Velayos M., et al. pediatric patients with acute appendicitis were evaluated in the months before and after the declaration of the pandemic in Spain. They saw a greater number of patients who consulted with fever, higher percentage of peritonitis, longer hospital stay and higher percentage of postoperative complications [6]. None of this conclusions was seen in our study.

Regarding the chosen boarding technique, the conventional boarding technique has been used more in our study, different from what was observed in the study of Velayos M., et al. in which in the pre-pandemic era the laparoscopic technique [6] has been used more. The most recommended boarding during the pandemic is controversial. Several studies shown that it should be chosen according to two priorities, individual patient conditions and availability in the workplace [7-10].

When we analyze the type of images requested to complement the diagnosis, it was seen that in 2020 a significantly lower percentage of abdominal X-rays were requested. Without consequences of a higher percentage of complications and bringing as a benefit the less radiation of the patients.

As previously mentioned, not many studies have been found that allow us to extrapolate the results of our study. However, it seems important to us to mention the frequent pediatric surgical pathology to strengthen the alerts that must be had when treating this population, in the context of a pandemic in which the symptoms could be mixed, generating a delay in diagnosis and therefore in the resolution of it.

In our work we decided to choose two equal time periods in both study groups, taking into account the importance of season- 
ality in pediatric pathologies; however, prolonging the evaluation months will probably allow us to reach more conclusive results. We consider this for a future update of this study.

\section{Conclusion}

We highlight that in the patients evaluated the appearance of advanced acute abdomen pictures was seen more in relation to the characteristics of the patients prior to the hospital stage than with the in-hospital stage for each of the groups evaluated, without seeing significant differences in the evolution and hospital stay between pre pandemic and during the course of it.

New hospital protocols for Sars-Cov-2 does not seem to have a negative impact on the evolution of cases of acute abdomen, allowing adequate care for health personnel.

It seems relevant to us to remember that SARS-Cov-2 can generate diagnostic confusion with frequent symptoms in pediatrics that may require surgical intervention. When thinking about diagnostic alternatives in a pandemic stage, is important to not forget that we saw in pediatrics over the years.

\section{Financing Support}

None to declare.

\section{Conflict of Interest}

None to declare.

\section{Acknowledgments}

We are grateful for the collaboration of Dr. María Marcela Bailez, general coordinator of Surgical Services of the Pediatrics Hospital "Prof. Dr. Juan P. Garrahan", who participated in the review of the results of the work and the entire General Surgery Service of the Pediatrics Hospital "Prof. Dr. Juan P. Garrahan" for the collaboration in collecting patients.

\section{Bibliography}

1 Huang L., et al. "Comparison of antibiotic therapy and appendectomy for acute uncomplicated appendicitis in children a meta-analysis". JAMA Pediatrics 171 (2017): 426-434.

2 Sun D., et al. "Clinical features of severe pediatric patients with coronavirus disease 2019 in Wuhan: a single center's observational study". World Journal of Pediatrics 16 (2020): 251-259.
3 Zhou Z., et al. "Effect of Gastrointestinal Symptoms in Patients with COVID-19". Gastroenterology 158.8 (2020): 2294-2297.

4 Villanueva M., et al. "Manifestaciones gastrointestinales y hepáticas de COVID-19 en niños". Revista Chilena de Pediatría 91.4 (2020): 623-630.

5 Blanco-Colino R., et al. "Suspected Acute Abdomen as an Extrapulmonary Manifestation of Covid-19 Infection". Cirugía Española 98.5 (2020): 295-296.

6 Velayos M., et al. "Influencia de la pandemia por coronavirus 2 (SARS-Cov-2) en la apendicitis aguda”. Anales de Pediatría 93.2 (2020): 118-122.

7 Página web del American College of Surgeons. Triaje y COVID-19 en cirugía general urgente (2020).

8 Página web de la Association of Surgeons of Great Britain and Ireland. Recomendaciones en cirugía y COVID-19 (2020).

9 Balibrea JM., et al. "Surgical Management of Patients With COVID-19 Infection. Recommendations of the Spanish Association of Surgeons". Cirugía Española 98.5 (2020): 251259.

10 Galiano Gil JM., et al. "Abdomen agudo durante la pandemia COVID-19". Revista Cubana de Cirugía 59.2 (2020): e957.

11 Polites SF and Azarow KS. "Perspectives on Pediatric Appendicitis and Appendectomy During the Severe Acute Respiratory Syndrome Coronavirus 2 Pandemic". Journal of Laparoendoscopic and Advanced Surgical Techniques 30 (2020): 356-357.

12 Li L., et al. "COVID - 19 patients' clinical characteristics, discharge rate, and fatality rate of meta - analysis". Journal of Medical Virology (2020): 1-7.

\section{Volume 4 Issue 10 October 2021 (c) All rights are reserved by Gisela Kesseler., et al.}

